\title{
Políticas de desenvolvimento territorial e multifuncionalidade da agricultura familiar no Brasil
}

\author{
Philippe Bonnal * \\ Renato S. Maluf* *
}

\section{Resumo}

Visando analisar de que maneira ações públicas voltadas para o meio rural vêm se referindo à noção de multifuncionalidade da agricultura e à perspectiva territorial do desenvolvimento, neste artigo são analisadas as diversas políticas públicas inscritas no Plano Plurianual 2004-2007. Num contexto marcado simultaneamente pela globalização da economia e pelo fortalecimento do processo democrático, destaca-se a preocupação dos gestores públicos de induzir um processo de reequilibração social e territorial mediante a implantação de duas lógicas distintas: políticas setoriais a favor da agricultura familiar e políticas de dinamização das atividades econômicas territoriais. Observa-se que essas políticas se referem de maneira implícita à multifuncionalidade da agricultura familiar e de maneira explicita ao enfoque territorial. Em conclusão, o artigo aponta o caráter essencialmente fragmentado e diferenciado das políticas de desenvolvimento rural e a necessidade de integrá-las mediante referências mais nítidas a ambas as noções.

Palavras-chave: Desenvolvimento territorial sustentável, políticas públicas, agricultura familiar, plano plurianual.

* Possui graduação em Agronomie pela Ecole D’ingénieurs Agro Développement (1978) e mestrado em Dea Economie Agro Alimentaire et Rurale pela Universite de Montpellier II (Scien. et Tech Du Languedoc) (1991). Atualmente é Pesquisador e consultor do Centre de Coopération Internationale de Recherche Agronomique Pour Le Dével.

*** Graduado em Ciências Econômicas pela Universidade Metodista de Piracicaba (1973), Mestre (1976) e Doutor (1988) em Economia pela Universidade Estadual de Campinas. Realizou programas de pós-doutoramento na Oxford University (UK) em 1996-7 e na Ecole des Hautes Etudes en Sciences Sociales (Paris), 2000-1. Atualmente é Professor Associado I do Programa de Pós-graduação em Ciências Sociais em Desenvolvimento, Agricultura e Sociedade, da Universidade Federal Rural do Rio de Janeiro (CPDA/UFRRJ). 


\section{Introdução}

$\mathrm{O}$ presente artigo tem por objetivo analisar programas públicos nacionais voltados, direta ou indiretamente, para a promoção da agricultura familiar e do agroextrativismo, o meio ambiente e o mundo rural, com a perspectiva de verificar em que medida as diretrizes gerais e a implementação desses programas contemplam elementos do enfoque da multifuncionalidade da agricultura (MFA) e a perspectiva territorial. Alerta-se para o fato de a pesquisa na qual se baseia o presente texto encontrar-se ainda em andamento ${ }^{1}$, estando prevista uma versão mais completa incorporando novas informações e eventuais contribuições oriundas da equipe da pesquisa e dos debates no próprio colóquio.

A perspectiva analítica aqui adotada assenta-se em duas premissas inter-relacionadas. A primeira assume que está em curso, desde meados dos anos 1990, a incorporação de elementos do enfoque da MFA no debate público e em diversas políticas agrícolas, ambientais e rurais no Brasil, ainda que na forma de uma apropriação fragmentada e quase sempre acessória ao núcleo central dos programas respectivos. Trata-se de um indicativo, sem dúvida importante, de inflexões em curso na orientação predominante nas políticas públicas, particularmente nas agrícolas e rurais, muito embora persistam dificuldades de várias ordens para revisar o foco quase que exclusivamente produtivo na "agricultura" familiar que caracteriza a maioria delas. A revisão desse foco levaria, também, a colocar as unidades familiares rurais - e não apenas os produtos por elas gerados - como objeto de atenção dos programas, ampliando deste modo o olhar sobre os papéis desempenhados pelas famílias rurais "para além da produção”.

Em paralelo à ainda incipiente valorização dos vários papéis cumpridos pela agricultura familiar, constata-se, também, que as

1 Esse artigo baseia-se nas pesquisas e debates realizados no âmbito do projeto 'Pesquisa e ações de divulgação sobre o tema da multifuncionalidade da agricultura familiar e desenvolvimento territorial no Brasil', UFRRJ-CPDA/REDES - NEAD/ IICA - 2006/2007. O projeto conta com pesquisadores oriundos das seguintes instituições: UFRRJ/CPDA, UFSC/CCA, UFRGS/PGDR, UERGS-FEPAGRO, EMBRAPACNPAM, USP/ESALQ, UFES, UFCG, CIRAD (França) e INRA (França; colaborador). 
políticas públicas têm caminhado na direção da "territorialização" das suas ações, inclusive como procedimento para obter maior coordenação entre elas. Desse movimento deriva um conjunto de questões de pesquisa relacionadas, desde logo, com as razões para a adoção da referência territorial e os próprios significados atribuídos à noção de território (ênfases, rupturas com abordagens anteriores, eventuais ganhos na regulação da ação pública, etc.). Integra essas questões a verificação dos atores envolvidos (e excluídos) e das percepções sobre os papéis da agricultura familiar no desenvolvimento territorial.

Ambos os enfoques, sobre os múltiplos papéis da agricultura e sobre os territórios, estão subjacentes às manifestações de retórica "não produtivista" que têm se multiplicado no Brasil - assim como em várias partes do mundo - em tensão com o linguajar hegemônico do agronegócio. Essas manifestações expressam preocupações com questões de equiidade social e sustentabilidade ambiental, ao mesmo tempo em que são portadoras de "novos" temas ou novos olhares sobre a atividade agrícola e o mundo rural, como, por exemplo, as questões de gênero e geracionais, modelos agroecológicos que questionam as relações com a natureza, a problemática amazônica e proposições específicas para comunidades rurais negras quilombolas e povos indígenas. Assim, admitindo-se que a adoção da perspectiva territorial e a apropriação do enfoque da MFA contribuem para contemplar as questões antes mencionadas, a pesquisa teve o objetivo de analisar duas ordens de implicações de uma revisão dos programas nessa direção. De um lado, no que se refere à concepção dos mesmos, particularmente, no desenho dos instrumentos de apoio às famílias rurais e de desenvolvimento territorial. De outro lado, nas iniciativas visando obter maior coordenação entre os programas pelo recurso ao enfoque territorial, cabendo verificar também a presença do enfoque da MFA nos espaços de interlocução social dos programas públicos e nas iniciativas de coordenação entre essas ações, haja vista a relevância assumida por esses espaços.

A dimensão da sustentabilidade tornou-se um componente essencial dos processos de desenvolvimento desde, ao menos, a década de 1980, sendo referência obrigatória em quase todos os programas e ações públicas em face da relevância adquirida pela 
temática ambiental em todo o mundo. Para nossos objetivos, essa dimensão pode ser abordada desde a ótica do desenvolvimento sustentável e relacionada com o tema geral da pesquisa por meio da noção de desenvolvimento territorial sustentável. Sabe-se que os significados atribuídos pelos programas públicos à noção de desenvolvimento sustentável são diversos e, não raro, contrastantes, característica que coloca a elucidação desses significados também como uma questão de pesquisa. As controvérsias e conflitos suscitados pela ótica da sustentabilidade refletem-se, naturalmente, na concepção dos programas de desenvolvimento territorial e na adequação dos respectivos instrumentos. A despeito da relevância do tema, porém, ainda não se logrou a plena incorporação do componente ambiental em todas as dimensões requeridas para se chegar a uma concepção de desenvolvimento territorial sustentável, de modo que nos limitaremos às indicações a respeito quando requeridas pelos enfoques da MFA e do desenvolvimento territorial.

Os três elementos antes apontados - valorização dos papéis não produtivos da agricultura familiar, enfoque territorial e desenvolvimento sustentável - devem ser abordados no contexto de fragmentação e diferenciação das políticas públicas, tendência que se generalizou como desdobramento do chamado ajuste estrutural (anos 1980) e da reforma do Estado, sobretudo nos países classificados como "em desenvolvimento" e "menos desenvolvidos". O Brasil não constituiu exceção, ao contrário, caminhou na direção desse padrão de políticas públicas que segue vigente no fundamental, mesmo considerando as modificações ocorridas no período aqui considerado (pós-2003). Veremos que ganham relevância programas que possam atuar como instrumentos de re-equilibragem social e territorial, ao mesmo tempo em que se colocam novas questões para as políticas setoriais.

$\mathrm{O}$ texto a seguir divide-se em quatro partes. A primeira apresenta a base conceitual e os procedimentos de pesquisa utilizados para efetuar a análise proposta dos programas. Na segunda parte, é feita uma contextualização da formulação de políticas públicas, seguida de uma análise das diretrizes gerais do Plano Plurianual 2004-2007, antecedendo a análise dos programas públicos escolhidos como objeto de investigação mais detalhada feita na terceira 
parte. A quarta e última parte contém as considerações finais na forma de um indicativo das conclusões da pesquisa a serem apresentada na versão definitiva do estudo.

\section{Base conceitual e método de pesquisa}

A pesquisa teve como ponto de partida o universo composto pelos programas públicos de âmbito nacional que incidem sobre a agricultura familiar e o mundo rural no Brasil, estabelecendo como período de análise o Governo Lula iniciado em 2003. Esse recorte cronológico deve-se a que nesse período foram introduzidos ou ganharam maior relevância nos programas públicos os elementos do enfoque da MFA e a perspectiva territorial mencionados na Introdução.

A abordagem aqui feita dos programas públicos recorre ao enfoque cognitivo pelo qual se busca apreender a construção do referencial das políticas, acompanhado da análise da construção de redes ou comunidades de políticas públicas. O enfoque cognitivo parte da premissa que o objeto das políticas públicas não se limita à resolução dos problemas da sociedade, se não que ele envolve também a construção de representações coletivas de interpretação da realidade baseadas em idéias e conhecimentos (MULLER, 2005). Este enfoque confere grande importância ao jogo dos atores institucionais e aos espaços de intermediação nos quais se constroem e se discutem essas idéias, razão pela qual o enfoque cognitivo das políticas públicas busca seus instrumentos de análise, principalmente, no campo da Sociologia Política ${ }^{2}$.

Entende-se por redes e comunidades de políticas públicas o conjunto de relações existentes entre grupos de interesse no sentido amplo da palavra, podendo fazer parte dessas redes e comunidades firmas, grupos profissionais, movimentos sociais e o Estado (BOUSSAGUET et. al., 2004). As noções de redes e comunidades fundamentam-se na premissa de que o processo de produção de

2 Muitos autores trataram do enfoque cognitivo. Ver o número especial da "Revue Française de Sciences Politiques”, N50 (2), abril-2000, particularmente, os artigos de Muller (2000) e Jobert (2000). Uma resenha interessante encontra-se em Faria (2003). 
políticas públicas é quase sempre fragmentado e pode mobilizar um grande número de atores privados organizados. As redes e comunidades correspondem a instituições não hierárquicas e horizontais que gozam de certa estabilidade. Embora essas noções recubram realidades variadas, a rede designa, geralmente, instituições mais estáveis que comunidades.

No que se refere ao método de pesquisa, pretende-se utilizar essas duas entradas conceituais de forma complementar. A noção de referencial de políticas públicas será ativada para analisar a emergência de novas idéias, olhares e normas coletivas sobre a agricultura e o mundo rural, particularmente, sobre a agricultura familiar e sua diferenciação em relação à chamada agricultura patronal, de modo a justificar o estabelecimento, aparentemente, consolidado de políticas agrícolas diferenciadas para ambos os segmentos. As novas referências originam-se dos debates em curso a respeito da sustentabilidade e do meio ambiente, da qualidade dos alimentos e dos aspectos identitários ou culturais a eles relacionados, da conformação de territórios, da questão patrimonial e, mais recentemente, da agroenergia. Serão também consideradas as relações, quase sempre de tensão, entre tais referências e a retórica produtivista convencional no âmbito nacional, assim como os debates internacionais sobre o papel da agricultura, o desenvolvimento sustentável e a competitividade agrícola. Já as noções de redes ou de comunidades de políticas públicas serão utilizadas para analisar o jogo institucional que sustenta a produção dos referenciais e a elaboração das políticas públicas, bem como para identificar e analisar as convergências ou oposições institucionais.

As duas fontes principais de informação a respeito dos programas públicos consistiram na análise documental e na realização de entrevistas com os respectivos gestores nacionais (detalhadas adiante). A primeira aproximação ao universo dos programas públicos se fez pela análise das diretrizes gerais, programas e ações constantes do Plano Plurianual 2004-2007 (PPA) do Governo Federal. Nessa etapa procurou-se identificar a ocorrência do uso e os significados atribuídos às palavras-chaves abaixo indicadas que remetem às quatro referências principais da pesquisa, a saber: 
- agricultura e rural;

- sustentabilidade e desenvolvimento sustentável;

- território e desenvolvimento territorial;

- papéis da agricultura e multifuncionalidade da agricultura.

O procedimento anterior oferece uma visão geral sobre a relevância, nos programas federais, das questões portadas pelas referências antes mencionadas. Além delas, adotou-se também um critério de escolha de programas considerados significativos, especificamente, para o tema da multifuncionalidade da agricultura familiar e o desenvolvimento territorial. A existência de políticas diferenciadas para a agricultura familiar torna forçoso escolher o Programa Nacional de Fortalecimento da Agricultura Familiar (PRONAF), e também o Programa de Desenvolvimento Sustentável dos Territórios Rurais (PDSTR) que combina o recorte social com uma entrada territorial. A elevada desigualdade social que marca o Brasil, com elevado peso de famílias pobres no meio rural, introduz um outro critério de diferenciação que são os domicílios rurais pobres e obrigaria a consideração do papel das políticas sociais como as contidas na Estratégia Fome Zero (Programa Bolsa Família e Programa de Aquisição de Alimentos da Agricultura Familiar) e a previdência social rural. A abordagem das políticas sociais não se enquadraria no objeto específico da pesquisa, de modo que será feita breve menção a um componente da Estratégia Fome Zero que é o Programa de Instalação de Consórcios Intermunicipais de Segurança Alimentar e Desenvolvimento Local (CONSAD).

Veremos que a relação com a questão da pobreza está também presente em programas ambientais como o Programa de Desenvolvimento Sócio-Ambiental da Produção Familiar Rural na Amazônia (PROAMBIENTE) e, de certo modo, no Programa Agenda 21. Outra é a lógica dos programas cujo foco principal é a dinamização de economias territoriais, como são os casos do Programa Arranjos Produtivos Locais e o Programa Gestão da Política de Desenvolvimento Regional e Ordenamento Territorial. Com esses programas ficam contempladas, ainda que de forma desigual, as cinco lógicas principais que presidem a descentralização ou territorialização das políticas públicas antes mencionadas. 
Em relação aos programas escolhidos, procedeu-se à análise documental das diretrizes e instrumentos, atores institucionais envolvidos e processos de implementação, bem como realizaram-se entrevistas com alguns de seus principais gestores nacionais. Essas entrevistas utilizaram um roteiro único semi-estruturado de questões, com o objetivo de complementar as informações recolhidas nos documentos e, especialmente, captar a visão dos entrevistados sobre as funções da agricultura familiar, como elas se expressam nos respectivos programas de desenvolvimento territorial e de desenvolvimento sustentável, bem como identificar os enfoques territoriais neles predominantes. Foram entrevistados seis gestores responsáveis pelos programas escolhidos para análise ${ }^{3}$ :

- Ministério do Desenvolvimento Agrário: PRONAF e PDSTR

- Ministério do Meio-Ambiente: PRO-AMBIENTE e AGENDA 21

- Ministério do Desenvolvimento, Indústria e Comércio: APL

- Ministério da Integração Nacional: PDR

- Ministério de Desenvolvimento Social e Combate à Fome: CONSAD

Antes, porém, de abordar esses programas, faremos uma contextualização das políticas públicas no Brasil.

\section{Contextualização das políticas públicas agrícolas e rurais e análise do PPA 2004-2007}

As políticas públicas de desenvolvimento territorial produzidas pelo Governo Lula vieram na sequiência das políticas estabelecidas, progressivamente, desde o fim do período militar, num contexto marcado pela emergência do modelo democrático-liberal e pelos movimentos, simultâneos, de reforma do Estado e abertura econômica cujas consequiências modificaram o quadro da formulação das políticas públicas. Nessa parte serão explicitados esses movimentos

3 Será realizada uma nova rodada de entrevistas com gestores e também com representações sociais nacionais a serem aproveitadas na versão definitiva do estudo. 
de reforma no período recente, seguida da apresentação das diretrizes gerais do Plano Plurianual 2004-2007.

\subsection{O contexto atual das políticas públicas territoriais}

O contexto de elaboração das políticas públicas territoriais, isto é a maneira como o território é tomado em conta nas políticas publicas, evoluiu fortemente durante as duas últimas décadas sob o efeito de uma evolução do referencial das políticas publicas tanto em nível internacional quanto nacional, assim como sob o efeito de mudanças importantes ocorridas no mundo rural no Brasil.

(i) No nível internacional

Distintos fatores contribuíram para a emergência de um novo referencial de políticas de desenvolvimento. O primeiro é a contestação progressiva do modelo de desenvolvimento que prevalecia desde os anos 1930. Como se sabe, as razões desta contestação estão ligadas à crise do processo de desenvolvimento econômico nos anos 1980 cujas principais manifestações foram a instabilidade monetária, o endividamento crônico, a desaceleração do crescimento econômico, o incremento da pobreza rural e urbana e a degradação dos recursos naturais. Cada um desses fenômenos alimentou um intenso debate nas instituições financeiras e agências de cooperação internacionais durante os anos 1980 (inflação, divida e crescimento) e 1990 (pobreza e gestão dos recursos naturais). O chamado Consenso de Washington, sintetizado pelo economista John Williamson, cristalizou os novos preceitos que deveriam nortear as políticas públicas nacionais. As propostas remetiam à redução do papel do Estado, ao respeito da disciplina fiscal e monetária, à privatização das empresas públicas e ao incentivo das exportações 4 .

Um segundo fator, resultante do anterior, foi a emergência da noção de governança, a qual pode ser entendida como processo de

4 A proposta de Williamson é compostas de 10 pontos agrupados em dois conjuntos de medidas: medidas para estabilizar a economia (redução dos subsídios, política monetária ortodoxa, taxa de cambio competitivo) e medidas estruturais (liberalização comercial, competitividade, privatização, desregulamentação dos mercados, reforma fiscal, fortalecimento dos direitos de propriedades). 
coordenação de atores, grupos sociais e instituições com vistas a realizar objetivos definidos e discutidos coletivamente (LE GALÉS, 1999). Esta noção, quando aplicada à gestão pública, remete à concepção das escolhas públicas (public choice) e é coerente com o corpus neoinstitucional. Ela recomenda a redução da estrutura estatal e a criação de uma rede de instituições presentes localmente com a finalidade de delegar a gestão territorial aos agentes locais - sociedade civil, representantes políticos, ONGs, empresariado, etc. - e dinamizar, assim, o chamado capital social territorial, ou seja, as interações sociais, políticas e econômicas singulares a cada território. Sugere também que o papel do Estado deveria limitar-se a incentivar a criação de instituições que facilitem e regulem mercados eficientes, estimulando a criação de instâncias regulatórias públicas, porém, não estatais.

Esta noção contribuiu para modificar o referencial sobre a descentralização dos programas públicos na direção do respeito do principio da subsidiaridade. A subsidiaridade é um principio de administração privada ou pública que considera que a decisão deve ser tomada pelo centro de decisão que (1) conheça melhor o problema e a maneira de solucioná-lo e (2) que tenha mais interesse na resolução do problema. Um terceiro fator é a emergência da preocupação com a sustentabilidade no debate sobre o desenvolvimento a qual incita os Estados a incluírem, cada vez mais, as dimensões ambientais e sociais nas suas estratégias de desenvolvimento econômico.

Essas mudanças de referencial tiveram ao menos dois tipos de consequiência no processo de elaboração de políticas públicas no nível nacional. Uma delas foi o abandono, de modo generalizado nos paises emergentes e em desenvolvimento, das políticas integradas e setoriais e sua substituição, de forma voluntária ou forçada ${ }^{5}$, por políticas segmentadas e diferenciadas. Isto é, políticas segmentadas focadas no tratamento específico de determinadas questões sem nexos diretos entre elas, e políticas diferenciadas especificamente reservadas a determinados segmentos sociais ou espaços geográficos. Esse processo de segmentação das políticas públicas

5 Pelas instituições financeiras internacionais, notadamente o Banco Mundial e o FMI nos casos em que o país tenha empreendido um processo de renegociação da sua divida externa. 
fundamentava-se no reconhecimento da capacidade regulatória dos mercados, cujas deficiências (dos mercados) deveriam ser corrigidas pela ação do Estado. Assim sendo, pode-se afirmar que as novas regras que passaram a nortear a ação pública tinham como principal justificativa a correção das externalidades negativas inerentes aos modelos de desenvolvimento baseados nos estímulos de mercado, de modo que as políticas públicas passam a ter a importante função de re-equilibragem social e territorial.

A segunda consequiência foi a modificação, a partir dos anos 1990, das regras de descentralização com a incorporação do já referido principio da subsidiaridade, ou seja, tentando redistribuir as responsabilidades do Estado ora entre os próprios órgãos públicos localizados em diferentes níveis de gestão (local, intermediária e nacional), ora criando espaços de mediação associando órgãos públicos e atores da sociedade civil. Em alguns casos, o papel do Estado fica reduzido, apenas, à mera função de coordenação entre atores locais provenientes da sociedade civil.

(ii) No nível nacional

Observa-se que as políticas atuais de desenvolvimento territorial se enquadram de maneira coerente dentro do processo de reforma político-administrativa que vem sendo realizado desde o início do período de redemocratização do país, em meados dos anos 1980, marcado pela instituição e fortalecimento do modelo democrático-liberal e que teve como principais eventos: a elaboração da Constituição democrática de 1988; a liberalização comercial e a reforma das instituições públicas federais; a resolução da crise monetária em 1994, após sucessivos planos; a reforma fiscal em 1998; a privatização de empresas públicas; o tratamento da crise da dívida. Observa-se, também, a implementação, embora muito incipiente, de políticas de ordenamento territorial e de desenvolvimento regional a partir dos anos 1990, conforme previsto na Constituição Federal de $1988^{6}$.

6 O ordenamento territorial é um preceito constitucional desde a Constituição de 1988, cujo Artigo 21, parágrafo IX estabelece que "compete à União elaborar e executar planos nacionais e regionais de ordenação do território e de desenvolvimento econômico e social". 
Já no período recente, vários outros acontecimentos, dependentes entre si, tiveram uma influência determinante no redirecionamento das políticas públicas rurais e territoriais. O primeiro deles, iniciado já nos anos 1980, foi o processo de reorganização dos movimentos sociais agrícolas e rurais que tinham visto reduzida sua capacidade de ação durante o período militar, assim como a progressiva integração entre eles para constituir, nos anos 1990, uma força reivindicatória independente com capacidade de negociação junto ao poder público. Como se sabe, essa reestruturação realizou-se na base de uma intensa reflexão interna aos movimentos sociais voltada para a redefinição das suas missões e estratégias, assim como de um importante trabalho de aprendizagem e criação de alianças e parcerias com organizações da sociedade civil e entes públicos. No caso dos sindicatos de trabalhadores e pequenos produtores rurais, essa mutação se expressou, notadamente, pelo investimento feito no temário da tecnologia agrícola e suas implicações sociais, ambientais e políticas.

Um segundo evento, diretamente ligado ao anterior, foi a emergência, durante os anos 1990, da agricultura familiar como categoria sócio-política, com capacidade de negociar junto ao Estado a elaboração de políticas públicas específicas. Esse reconhecimento inscreve-se na ruptura com a estruturação do poder político no campo, tradicionalmente, assumido de forma não compartilhada pelas elites agrárias. Outro fato importante, sempre na lógica da reorganização social e política no campo, foi a emergência de referenciais próprios para as agriculturas familiares e diversas identidades (povos indígenas, comunidades quilombolas, pescadores artesanais, ribeirinhos etc.), que serviram de base para a discussão, junto aos poderes públicos, de políticas diferenciadas. Essas referências emergiram e se desenvolveram graças às alianças construídas com as organizações, redes e movimentos sociais em nível nacional e internacional (como a Via Campesina).

Enfim, como resultante desses diversos acontecimentos, observou-se durante os anos 1990 e 2000 a multiplicação de iniciativas coletivas realizadas pelos movimentos sociais em articulação com ONGs, com vistas a identificar, experimentar e implementar respostas concretas aos desafios tradicionais dos agricultores familiares. 
Algumas dessas experiências se tornaram, por sua vez, referências para a definição de políticas públicas específicas como, por exemplo, a questão do acesso à água por parte da Articulação do Semi Árido (ASA), ou a gestão técnica, social e ambiental da agricultura pela Associação Nacional de Agroecologia (ANA).

Ao observar a evolução das políticas públicas durante a última década, ressalta-se, em primeiro lugar, a continuidade entre os governos de FHC e de Lula na preocupação de fortalecer os agricultores familiares mediante políticas diferenciadas de crédito rural, reforma agrária e transferências sociais. Contudo, o governo Lula distingue-se do anterior pelo maior peso conferido às políticas de re-equilibragem social e territorial. Esta orientação se expressa na (i) reativação da preocupação territorial, (ii) ampliação e integração das políticas sociais de combate à pobreza (Fome Zero) e (iii) diversificação das linhas de crédito destinadas às famílias rurais. Observa-se, também, que a abordagem territorial integra tanto os enfoques recentes veiculados pelo novo referencial internacional sobre subsidiaridade - como são os casos do programa APL (Arranjos Produtivos Locais) ou do Fórum de Desenvolvimento Territorial da SDT/MDA - quanto os referenciais mais antigos sobre ordenamento territorial e desenvolvimento regional. Desde esse ponto de vista, assiste-se, no governo Lula, à retomada da retórica do desenvolvimento, embora ainda limitada na sua efetividade.

\subsection{Diretrizes e prioridades do período recente: o Plano Plurianual 2004-2007}

As características gerais do contexto antes apresentado estão, de algum modo, presentes no Plano Plurianual (PPA) 2004-2007 intitulado "Plano Brasil de Todos - Participação e Inclusão - Orientação Estratégica de Governo: crescimento sustentável, emprego e inclusão social”, formulado no início do Governo Lula. Sabe-se que os PPAs são documentos com formulações bastante genéricas que, ademais, nem sempre orientam as ações e programas de governo, porém, constituem importante registro de intenções e um ponto de partida para a análise dessas ações e programas. Conforme antecipado, a primeira aproximação da pesquisa ao universo dos programas 
públicos no período em questão se baseou na análise documental do PPA 2004-2007. O Plano teve por objetivo planejar a retomada do desenvolvimento do país com uma preocupação de equidade social, implicando a mobilização da sociedade brasileira em torno da superação da fome e da miséria. Nesse sentido, identificava como principais problemas a serem enfrentados a concentração de renda e da riqueza, a exclusão social, a baixa criação de emprego e as barreiras para a transformação dos ganhos de produtividade em aumento de rendimentos da maioria das famílias trabalhadoras.

Ao Estado foi atribuído papel decisivo de agente "condutor do desenvolvimento social e regional e indutor do crescimento econômico", orientado por um "projeto de desenvolvimento" e "claras políticas setoriais", para além dos necessários programas de emergência. Importa destacar, no diagnóstico sobre as carências percebidas na atividade de planejamento, a abertura para o enfoque territorial na medida em que as desigualdades espaciais figuram ao lado das preocupações com a desigualdade social e a pobreza. Segundo um gestor entrevistado, a introdução da dimensão territorial, em 2003, pretendeu adotar a perspectiva da construção de consensos sobre projetos de desenvolvimento, em substituição ao enfoque utilizado em 1995 que se baseava em "eixos de desenvolvimento" orientadores dos investimentos governamentais em infraestrutura 7 .

Assim, três mega-objetivos conformavam as estratégias de longo prazo do PPA 2004-2007:

Inclusão social e desconcentração de renda com crescimento do produto e do emprego;

Crescimento ambientalmente sustentável, redutor das disparidades regionais, dinamizado pelo mercado de massa, por investimento e pela elevação da produtividade;

7 Vale mencionar duas premissas atribuídas pelo entrevistado ao enfoque territorial: (a) os territórios têm maior densidade política que as ações de desenvolvimento regional (desenvolvimento regional é parte do desenvolvimento territorial); (b) os territórios são unos, apesar de plurais na sua composição. A segunda premissa não implica que os "territórios" dos programas públicos consigam expressar essa pluralidade. 
Redução da vulnerabilidade externa por meio da expansão das atividades competitivas que viabilizem esse crescimento sustentado.

As políticas e programas do PPA foram distribuídos em cinco dimensões principais: (i) social; (ii) econômica; (iii) regional; (iv) ambiental; (v) democrática. Nota-se que as questões ambientais e de ordenamento espacial figuram (explicitamente) tanto nas estratégias de longo prazo quanto em duas das cinco dimensões. Contudo, a estabilidade macroeconômica ocupa posição de elemento central na consolidação do projeto de "desenvolvimento sustentável”, ao lado das políticas voltadas à expansão da renda e do consumo dos mais pobres a um ritmo superior ao do crescimento da renda e do consumo dos mais ricos. O PPA aponta como objetivo de longo prazo "inaugurar um processo de crescimento pela extensão do mercado de consumo de massa e com base na incorporação progressiva das famílias trabalhadoras ao mercado consumidor".

O documento reconhece que "o mercado" não pode ser o único determinante do ordenamento territorial, sob o risco de promover a concentração econômica e acirrar as desigualdades sociais. Decorre daí a regionalização de políticas e programas visando reduzir desigualdades entre as regiões e as disparidades internas às regiões. Prevê ainda que "[a] rica diversidade regional será empregada como um ativo na regionalização do nosso desenvolvimento, de forma compatível com o requisito fundamental da sustentabilidade ambiental" (MPOG, 2004, p.12). Apesar de o ordenamento territorial figurar como um dos pilares da estratégia de governo, o documento não detalha as formas de intervenção no nível territorial que atendam às restrições ambientais, mais além da afirmação genérica do respeito à diversidade regional e do uso sustentável dos recursos naturais existentes nas diferentes regiões brasileiras.

Vejamos o núcleo dos conteúdos das cinco dimensões destacadas no PPA:

Dimensão social

Tem por objetivos a inclusão social e a redistribuição da renda, com uma ampla agenda de políticas sociais entre as quais destacamos as que se relacionam com o direito de acesso universal 
a serviços sociais de qualidade (previdência, assistência, saúde, educação, capacitação, etc.), geração de emprego e renda e melhoraria das condições de trabalho (apoio à agricultura familiar, reforma agrária, micro-crédito e reforma trabalhista) e ações dirigidas à população mais vulnerável.

\section{Dimensão econômica}

Para promover o crescimento estável da renda e a ampliação do emprego em quantidade e qualidade, priorizava o fortalecimento da competitividade exportadora, a conquista de mercados internacionais e a substituição de importações. Menciona, também, o fomento de pólos e arranjos produtivos locais, o fortalecimento das grandes empresas nacionais, o apoio às pequenas e médias empresas, a atração de investimento direto estrangeiro e, por seus efeitos geradores de divisas, enfatiza o turismo, a agricultura, a mineração e as atividades de exportação e produção substitutiva de importações.

Dimensão regional

$O$ reconhecimento de que as desigualdades sociais possuem uma dimensão regional acarreta seu enfrentamento por meio da execução de uma política de desenvolvimento regional e o fortalecimento do planejamento territorial no setor público. Propugna a substituição do processo assimétrico de desenvolvimento sócioeconômico pelo desenvolvimento solidário entre as regiões, potencializando as vantagens da diversidade cultural, natural e social. A ênfase na dimensão econômica da diversidade (potencialidades econômicas do Nordeste, da Amazônia e do Centro-Oeste) e a atenção diferenciada às zonas deprimidas, eram acompanhadas da proposta de olhar o território nacional nas diversas escalas visando a coesão social e econômica. Esse raciocínio é transposto ao gasto social e às políticas de emprego e renda, além de embasar a perspectiva de fazer convergir as prioridades entre os entes federativos. Os arranjos produtivos locais seria o instrumento de desconcentração espacial da produção e valorização de recursos dispersos.

Dimensão ambiental

Adotando uma ótica de desenvolvimento sustentável que vincula os compromissos de justiça social com as gerações atuais ao 
legado para as gerações futuras, o documento evidencia a estreita relação entre pobreza, precariedade das formas de produção e meio ambiente, ou entre degradação ambiental e degradação social. Não menos importante, a estratégia propugna por um crescimento econômico com "abordagem qualitativa", com manejo sustentável dos recursos naturais e coibindo ações produtoras de desequilíbrios ambientais. Os conflitos de interesse e de responsabilidade pelos custos ambientais e sociais demandam construir "pactos", com destaque para a relação da agricultura com o meio ambiente. Reaparece, aqui também, a ênfase na dimensão econômica da diversidade cultural das populações associadas (ou não) às reservas ambientais e ao meio ambiente (ecossistemas e biomas).

Dimensão democrática

Visando fortalecer a cidadania e garantir direitos humanos, bem como dar transparência ao setor público e um planejamento participativo, a estratégia previa o desenvolvimento de relações plurais e democráticas baseadas na equidade e com oportunidades iguais em todos os aspectos da vida social. Destaque é dado aos segmentos sociais tradicionalmente excluídos. Nesse ponto são feitas, também, referências ao estabelecimento de "pactos" e a um novo contrato social que favoreçam o nascimento de uma cultura política de defesa das liberdades civis e dos direitos humanos, bem como a construção de um país mais justo econômica e socialmente e, sobretudo, um Estado adaptado às exigências deste "novo ciclo de desenvolvimento".

Por fim, quanto ao uso das palavras-chaves que compõem o escopo da presente pesquisa, nota-se no PPA o uso mais frequiente de "sustentável" e "sustentado", porém, atrelados ora à idéia de crescimento, ora à idéia de desenvolvimento. Os termos "sustentável" e "sustentado" intercalam-se no texto ao lado das palavras "crescimento" (sustentado: 08 vezes; sustentável: 03 vezes) e "desenvolvimento" (sustentado: 02 vezes; sustentável: 04 vezes), ao passo que os termos "desenvolvimento" e "crescimento" aparecem sem qualificação ou acompanhados de outras adjetivações como "solidário", "local” ou "regional".

A inconstância de definições no documento sugere, ademais, tratar-se apenas de uma alternância no uso dos termos à medida 
que as dimensões e programas do PPA vão sendo apresentados. No entanto, isto se processa de tal forma que é possível diferenciar uma sutil distinção nos usos de "sustentável" e de "sustentado", com o primeiro sendo normalmente atrelado ao desenvolvimento quando este comporta questões relacionadas com o meio ambiente e o uso dos recursos naturais pelas gerações presentes e futuras, enquanto que o segundo está mais ligado à idéia de sustentação do projeto de crescimento macroeconômico rumo ao desenvolvimento.

As demais palavras-chaves aparecem no documento com frequiência menor e de um modo que reflete as especificidades de suas relações com as políticas e dimensões estabelecidas no PPA. Vale dizer, enquanto o desenvolvimento sustentável aparece como referência transversal a todas as políticas e dimensões, as demais estão citadas de forma mais pontual. Assim:

território/desenvolvimento territorial - enfocado na perspectiva do "ordenamento territorial" como política regional estabelecida para fortalecer o planejamento no setor público; alerte-se, porém, que o documento refere-se mais a regional que a territorial;

agricultura familiar/desenvolvimento rural - considerados no âmbito das políticas de inclusão social que possibilitam a fixação das famílias no campo e a geração de trabalho e renda.

Feita essa breve apresentação das diretrizes gerais do PPA 2004-2007, abordaremos na sessão seguinte os programas que guardam relação com as questões da multifuncionalidade da agricultura e desenvolvimento territorial, seguindo procedimento antes explicado. Note-se que a adoção de enfoques de tipo territorial na formulação e implementação dos programas que envolvem o mundo rural foi acompanhada pela utilização explícita da noção de multifuncionalidade, como, por exemplo, no plano de reforma agrária ("valorizar a multifuncionalidade do espaço rural"; "a agricultura familiar promove uma ocupação mais equilibrada do território nacional e por meio de sua multifuncionalidade e da pluriatividade integra diferentes contribuições ao território e diferentes atividades econômicas") e no PROAMBIENTE ("o espaço rural adquire um novo papel perante a sociedade, pois seus atores sociais deixam de ser apenas fornecedores de produtos primários, sendo valorizado o caráter multifuncional da produção econômica associada com a 
inclusão social e conservação do meio ambiente"). Em direção contrária atuam os fatores que restringem a incorporação do enfoque da MFA, como são os elevados índices de pobreza rural, a persistência de restrições no acesso à terra e a pressão exercida pela expansão das grandes explorações e da monocultura resultante da ampliação das exportações agropecuárias, do avanço do reflorestamento e da produção de agrocombustíveis.

\section{Enfoque territorial, sustentabilidade e papéis da agri- cultura em programas de apoio à agricultura familiar}

Vimos que a abordagem aqui adotada sobre a evolução recente das políticas públicas no Brasil, assim como em outras partes do mundo, coloca ênfase em duas preocupações principais que as movem no contexto geral de segmentação e diferenciação dessas políticas. Uma das preocupações é promover processos de re-equilibragem social em face das desigualdades geradas pelas dinâmicas econômicas dominantes; em particular, essa perspectiva tem levado à definição de políticas especificas para a agricultura familiar e também para as populações rural e urbana pobres. A segunda preocupação vai na direção de promover a re-equilibragem dos espaços econômicos nacionais com base em políticas territoriais ou regionais; nesse caso, iremos encontrar programas de desenvolvimento de territórios rurais ou com entrada pela dimensão ambiental. Ambos os enfoques - social e territorial - podem aparecer de forma interligada, como vimos no diagnóstico que figura no PPA 2004-2007 e prevê o enfrentamento simultâneo das desigualdades sociais e espaciais. Contudo, raramente, a formulação e implementação dos programas contemplam a complexidade dos respectivos contextos sócio-espaciais ou logram obter entre eles (os programas) o grau de coordenação necessário para enfrentar ambas dimensões da desigualdade.

Nessa seção iremos nos concentrar em programas voltados para o desenvolvimento territorial ou que tenham em conta essa dimensão, guardada a relação com as questões da multifuncionalidade da agricultura familiar. As políticas territoriais atuais obedecem a cinco lógicas principais que se manifestam isoladamente ou de forma combinada nos diferentes programas públicos, a saber: 
Dinamização das atividades econômicas;

Implementação de infra-estrutura física;

Gestão de recursos naturais;

Construção e/ou promoção de identidades;

Aperfeiçoamento da governança.

A adoção de políticas territoriais não se dissocia, ao contrário, interage com a lógica de implementação descentralizada de programas públicos, particularmente, das políticas sociais que envolvem a prestação de serviços públicos, entre outras, por razões de eficiência e de participação e controle social. Esse processo foi também influenciado, ao longo do caminho, pelos enfoques derivados do princípio da subsidiaridade (referido na parte anterior) e da perspectiva de “interiorização do desenvolvimento". Nunca é demais relembrar um fator da maior relevância no caso brasileiro, assim como em alguns outros países, que são as características do pacto federativo e o poder político e relativa autonomia existente na esfera dos governos estaduais. De todo modo, a ótica da descentralização com o sentido antes indicado antecedeu, no Brasil, a própria incorporação do enfoque territorial. Talvez seja possível classificar a descentralização como uma modalidade de 'territorialização' das políticas públicas que, na tipologia acima, reflete uma lógica de governança e compõe um dos movimentos ("de cima para baixo") do enfoque territorial, ao lado dos determinantes "de baixo para cima".

Cinco ministérios e alguns dos seus programas destacam-se no tocante às iniciativas de tipo territorial no Brasil, considerada a temática da pesquisa. Os Ministérios do Desenvolvimento Agrário (PRONAF e PDSTR) e do Meio Ambiente (PROAMBIENTE e Agenda 21) concentram boa parte das políticas diferenciadas de apoio à agricultura familiar e relativas ao meio-ambiente, combinando elementos das cinco lógicas acima, porém, com ênfase nas três últimas (recursos naturais, identidades e governança). Já o programa de arranjos produtivos locais do Ministério de Desenvolvimento, Indústria e Comércio tem como foco a dinamização de atividades econômicas. O Ministério da Integração Nacional, cujo programa de desenvolvimento regional é centrado na dinamização econômica e na infra-estrutura, incumbiu-se também da coordenação das várias 
políticas territoriais do Governo Federal. A relevância assumida pelas políticas sociais no Brasil requer mencionar a Estratégia Fome Zero capitaneada pelo Ministério de Desenvolvimento Social e Combate à Fome (MDS) e englobando programas muito diversos, dos quais mencionaremos, brevemente, os CONSAD's por sua relação com o objeto da pesquisa.

Não será feita a apresentação dos programas, de resto bastante conhecidos, mas apenas destacados os elementos que interessam, mais diretamente, à pesquisa, tendo por base fontes documentais e informações obtidas nas entrevistas com seus gestores.

\subsection{Políticas setoriais diferenciadas de apoio à agricultura familiar}

Apoio creditício à agricultura familiar

Não restam dúvidas sobre a importância do Programa Nacional de Fortalecimento da Agricultura Familiar (PRONAF) em vários sentidos, começando pelo próprio significado da sua criação. Em linha com o novo contexto de formulação de políticas públicas salientado anteriormente, o PRONAF constituiu o primeiro e mais importante exemplo de política setorial diferenciada dirigida para a agricultura e o mundo rural no Brasil, mais precisamente, uma política diferenciada segundo um recorte social que define uma categoria de agricultor/a a qual se associa um tipo de agricultura. Uma segunda característica importante do programa foi ter introduzido, nesse domínio, a perspectiva de formulação e implementação de políticas públicas com participação social na forma de conselhos nas três esferas de governo, e também na prática de negociações periódicas das pautas apresentadas ao governo pelos movimentos sociais, principalmente, nos momentos que antecedem a definição anual dos principais componentes do programa. Por fim, o PRONAF também se converteu num instrumento de introdução de políticas territoriais no meio rural, conforme se destacará a seguir.

O que poderia ser considerado como a "territorialização" do PRONAF se iniciou como contraponto à apropriação inicial das linhas de crédito do programa pelas regiões com agricultura familiar mais 
consolidada, no Centro-Sul do país. Uma das quatro linhas de atuação do programa, denominada Pronaf-Infraestrutura, visou atuar, inicialmente, nas regiões empobrecidas com infraestrutura precária e cujos agricultores familiares enfrentavam dificuldades para acessar o crédito agrícola e outras políticas públicas, especialmente, em municípios do Nordeste brasileiro. A esse objetivo somava-se, no dizer atual dos gestores, a pretensão de tomar em conta elementos da pluriatividade das famílias rurais e da multifuncionalidade da agricultura familiar - embora, à época, ela não aparecesse formulada nesses termos - em circunstâncias onde não caberiam as chamadas políticas agrícolas clássicas (isto é, de crédito à produção) baseadas na capacidade produtiva das famílias rurais. Fica, então, evidente que o recurso ao "território" constituiu estratégia de reequilibragem espacial (e social) nos termos apontados na seção anterior. Neste caso, o território do programa ("território dado") correspondia à unidade político-administrativa básica (município) para a descentralização do Pronaf-Infraestrutura. Ultrapassa os objetivos da pesquisa realizar uma avaliação da implementação do Pronaf-Infraestrutura que, como sabe, viria a ser substituído pelo Programa de Desenvolvimento Sustentável dos Territórios Rurais (PDSTR) com a intenção de construir territórios de identidade, conforme abordado mais adiante.

O PRONAF logrou superar, em grande medida, a assimetria verificada nos primeiros anos do programa, com uma melhor distribuição dos recursos entre as regiões brasileiras e também entre as diferentes categorias de agricultores familiares (Schneider et al., 2004). Destaque-se, também, o contexto recente de expansão acelerada do PRONAF-crédito que se aproxima da marca dos 2 milhões de contratos, num universo estimado de 4 milhões de estabelecimentos familiares no Brasil. Não obstante essa expansão e a diversificação das modalidades de crédito, a capacidade de o programa atuar como instrumento promotor de desenvolvimento rural defronta-se, segundo seu gestor, com limites impostos pelo fato de o programa não ser adequado para a base da pirâmide social dos agricultores familiares que constitui "pauta sócio-econômica referente à pobreza e desenvolvimento". Essa base é composta pelos assentados da reforma agrária e partes dos agricultores en- 
quadrados nas categorias B e C do Pronaf, englobando cerca de um milhão de famílias rurais.

Importa salientar que a operação do PRONAF-crédito já está, plenamente, municipalizada, expressando uma lógica de descentralização na qual os limites do "território" da política setorial são definidos por critérios político-administrativos e sua implementação se vale das estruturas de governo (prefeituras e governos estaduais) e do sistema bancário. Ainda que também esteja sob influência dos governos estaduais e municipais, veremos que a lógica territorial do PDSTR é diferente da do PRONAF, acarretando duas dinâmicas distintas no interior de um mesmo Ministério (MDA) cuja coordenação não parece garantida à priori. Um instrumento que pode levar à maior e, nesse aspecto, desejável coordenação entre os dois programas é o recém criado Plano de Safra Territorial. A instituição dos Planos de Safra da Agricultura Familiar pelo MDA, desde 2003, constituiu mais um instrumento de diferenciação frente aos Planos de Safra convencionais elaborados, anualmente, pelo Ministério da Agricultura. Os planos de safra territoriais têm a perspectiva de adequar o apoio creditício às condições particulares de cada território, de modo integrado aos planos territoriais de desenvolvimento rural sustentável. Note-se, ademais, que esse procedimento abre a possibilidade de maior participação dos atores locais no direcionamento do crédito agrícola.

Para concluir a referência aos rumos recentes do PRONAF, cabe destacar o modo como esse programa vem refletindo a emergência de preocupações relativas ao meio-ambiente e à sustentabilidade e a diversas questões de desenvolvimento rural, as quais, entre outras implicações, constituem tentativas de superar os limites do crédito agrícola tradicional que tem por base a produção de um bem e é, ademais, implementado através do sistema bancário, portanto, sob influência da lógica bancária comercial. "Novos" temas e instrumentos vêm sendo incorporados ao programa, levando a criação de linhas diversificadas de financiamento (mulheres, jovens rurais, agroecologia, Semi-Árido, pesca, florestal, turismo, entre outras) e outras linhas de atuação como nos casos do seguro e da assistência técnica e extensão rural. O seguro agrícola convencional associado à lógica bancária - de fato, um seguro do crédito feito - tem dado 
lugar ao "seguro da agricultura familiar" que garante a cobertura de $100 \%$ do financiamento mais $65 \%$ da receita liquida esperada pelo empreendimento financiado pelo(a) agricultor(a) familiar; com sentido análogo, o "garantia-safra" visa propiciar segurança ao exercício da atividade agrícola na região Semi-árida brasileira, oferecendo ao agricultor cuja safra é afetada pela uma renda por tempo determinado (R\$ 110,00 mensais durante cinco meses) para as culturas de arroz, milho, feijão, algodão e mandioca. Mais importante em termos das questões colocadas pela pesquisa, cabe destacar a implantação de um "crédito sistêmico" para o conjunto da propriedade reunindo o financiamento de custeio e de investimento, bem como a incorporação do enfoque no "espaço rural" e a chamada "janela verde" oferecida para a agricultura familiar pela crise ambiental e pela demanda por alimentos limpos.

Os desafios antes apontados refletiram-se, também, na área de assistência técnica e extensão rural (ATER), dando origem, em 2003, a uma política nacional com a pretensão de recuperar o sistema nacional de ATER, praticamente, desmontado na década de 1990. A perspectiva é promover o desenvolvimento da agricultura familiar pela oferta gratuita desse serviço com caráter educativo e metodologias participativas, "[política] orientada pelos princípios da agroecologia, visando a implementação de estratégias de desenvolvimento ambientalmente sustentável, economicamente viável, sócio-culturalmente aceitável e que respeitem as diversidades existentes no país, visando a universalização do conhecimento no campo, o resgate da cidadania, a inclusão social e a melhoria da qualidade de vida da população, com estímulo à produção de alimentos sadios e de melhor qualidade biológica [incorporando] em todas as suas dimensões, as questões relativas a gêneros, raças e etnias, elaborando conteúdos e formas de ação que contemplem estas especificidades". Iniciativa análoga foi a criação pelo Instituto Nacional da Reforma Agrária, em 2004, da Assessoria Técnica, Social e Ambiental à Reforma Agrária (ATES), como alternativa para prestar serviços de extensão rural para agricultores assentados.

Programa de desenvolvimento dos territórios rurais

O Programa de Desenvolvimento Sustentável dos Territórios Rurais, implementado pela Secretaria do Desenvolvimento Territorial 
(SDT) do MDA, é uma das políticas do atual Governo Federal que mais se diferencia das vigentes nas gestões anteriores, por razão tanto do processo escolhido para sua elaboração, quanto do tipo de recorte territorial que aplica. Efetivamente, ao escolher elaborar a política pública a partir da articulação de dinâmicas sociais locais, a SDT se afastou da tradição da planificação pública descendente e centralizada. Da mesma maneira, a SDT inovou quando determinou trabalhar em cima de territórios "construídos" que se diferenciam das unidades administrativas estabelecidas pela Constituição de 1988. Segundo a secretaria geral, a criação da SDT, que ocorreu em 2004, tinha como perspectiva principal enfrentar o problema do acesso às políticas agrícolas clássicas, incorporando os enfoques da pluriatividade e da multifuncionalidade em regiões onde a situação agrícola era socialmente complexa.

Apesar de ser originado de iniciativa do antigo CNDRS (Conselho Nacional de Desenvolvimento Rural Sustentável), a formulação do Programa de Desenvolvimento Sustentável dos Territórios Rurais (PDSTR) se realizou de maneira simultânea a sua implementação, na continuação de uma reflexão conduzida, durante o período de transição para o Governo Lula, por atores políticos governamentais e oriundos de organizações não-governamentais (ONG's), com apoio de universitários. Na prática, a implementação do programa se realizou em três fases sucessivas definidas "na marcha". A primeira fase aconteceu, basicamente, durante os anos 2003 e 2004, tendo sido consagrada à definição do programa, à formação do pessoal envolvido, à definição de uma metodologia de seleção dos territórios e à identificação dos primeiros territórios pelos Conselhos Estaduais de Desenvolvimento Rural Sustentável (CEDRS). A segunda fase correspondeu à qualificação dos instrumentos de apoio à implementação dos projetos. Por fim, a terceira fase foi dedicada à definição das regras de gestão dos projetos e de governança territorial (criação dos colegiados), bem como ao fortalecimento social mediante a formação e capacitação do pessoal envolvido, à articulação das políticas públicas e ao apoio ao desenvolvimento econômico. Durante essas diferentes fases, consolidou-se uma preocupação na SDT de tomar em conta atividades econômicas não-agrícolas tais como o artesanato, e também de considerar os aspectos culturais 
locais, apesar das dificuldades ligadas à ausência de instrumentos de intervenção adequados e da forte marca do enfoque agrícola prevalecente no Ministério do Desenvolvimento Agrário.

Chama a atenção a forte preocupação do programa com a redução das assimetrias sociais e geográficas no meio rural, dentro e entre as regiões naturais do país. Entende que a redução da desigualdade passa pelo apoio discricionário do Estado em benefício dos componentes mais fragilizados da sociedade rural, nomeadamente, agricultores familiares, assentados da reforma agrária e acampados, extrativistas e comunidades remanescentes de quilombos. A preocupação de re-equilíbrio social e territorial faz com que o programa da SDT se ancore tanto nas políticas de redução da pobreza rural, quanto nas políticas de desenvolvimento territorial. Ele se encontra, portanto, em posição complementar às políticas públicas voltadas, especificamente, para a redução da pobreza rural através de transferências sociais (Fome Zero) ou para o desenvolvimento regional baseado em incentivos econômicos de estímulo à iniciativa privada ou de investimentos públicos de infra-estrutura.

Para elaborar o programa, a SDT se inspirou em experiências de desenvolvimento rural de algumas organizações não-governamentais e movimentos sociais oriundas, basicamente, do Nordeste. Foram determinantes as experiências dos projetos Assocene (Projeto Umbuzeiro), Dom Helder Câmara e Pólos Sindicais, na determinação da estratégia de ação da SDT. Pesquisadores universitários e técnicos de agências de cooperação, principalmente, do Instituto Interamericano de Cooperação Agrícola (IICA), foram também consultados para nutrir a reflexão no tocante à maneira de tratar os dois conceitos sobre os quais se fundamenta a política, quais sejam, "ruralidade" e "territorialidade".

Em termos conceituais, a SDT concebe o território como um espaço geográfico construído em torno de uma identidade local. A referência à "identidade" deve ser entendida como um duplo convite. De um lado, ela é uma incitação para reivindicar um tratamento diferenciado com base numa especificidade afirmada, seja ela cultural, econômica ou ambiental (extrativistas, quilombolas, etc.). De outro lado, ela é um convite para empreender ações coletivas em vista da construção de uma imagem coletiva, que possa dar sentido 
a projetos específicos locais. Esta acepção do conceito de território é coerente com a vontade da Secretaria de promover uma dinâmica programática ascendente e participativa, mas ela é também complementar com as políticas de desenvolvimento territorial de outros órgãos públicos. Assim sendo, a SDT se preocupa em estabelecer articulações com outros programas públicos territoriais tais como: Luz para todos (MME), CONSAD (MDS), Educação no Campo (ME), SENAES-Economia solidária (MTE). Contudo, é com o MMA que a SDT tem maior vinculação, apesar de as articulações terem sido pontuais e até incipientes devido a divergências nas orientações entre ambos ministérios.

Programas de desenvolvimento sustentável

A integração do imperativo de um desenvolvimento territorial sustentável é evidenciada em vários programas setoriais coordenados pelo Ministério do Meio Ambiente que agregam as dimensões ambiental e territorial. A colocação do desenvolvimento sustentável entre os desafios estratégicos do Ministério obrigou uma visão mais integrada de território que não seria necessária caso a opção houvesse sido pelo enfoque da proteção ambiental. O diagnóstico de que há vários programas com enfoque nos territórios mas que não atuam de modo integrado (ordenamento territorial, zoneamento ecológico-econômico, Agenda 21 e PROAMBIENTE) levou à adoção do enfoque territorial para rever instrumentos de gestão ambiental com vistas a superar a fragmentação das ações, dar consistência a elas e promover sinergias, incluindo a criação de um Departamento de Gestão Ambiental e Territorial.

A relação entre agricultura, ambiente e território fica clara na estratégia central do MMA, segundo um seu gestor, que é organizar a produção em outras bases de modo a que aumentos de produtividade e a ocupação de áreas degradadas tornem desnecessária a utilização de novas áreas na Amazônia; essa estratégia atuaria como instrumento complementar à proteção ambiental. Particularmente relevantes para a pesquisa são as interfaces entre as questões ambientais (MMA) e da agricultura familiar (MDA) que se manifestam nos programas do MMA dirigidos para a agricultura. Uma delas diz respeito ao Programa Gestão Ambiental Rural (GESTAR), herdado do Governo FHC, que reviu suas referências territoriais em direção mais 
próxima dos critérios identitários do PDSTR/MDA, porém, visando um envolvimento mais amplo de atores. Apesar da perspectiva de integrar ambos os programas, a relação entre eles tem envolvido conflito de atuação pelo foco limitado do CIAT na agricultura familiar, deixando de fora setores importantes e muitas vezes os mais problemáticos (como madeireiros na Amazônia), conforme já apontado.

Os programas do MMA voltados para a agricultura (PROAMBIENTE e outros) atingiram, em 2006, cerca de 140 mil famílias rurais com foco na inclusão produtiva de populações rurais marginais, quase todas sem acesso ao PRONAF. Daí que eles operam com lógica diferenciada e flexível, sem natureza bancária (valem-se de 'agência implantadora' não governamental), recursos não reembolsáveis (fundo perdido) e projetos complexos (sistemas agroflorestais sem referência a um produto específico). Os planos de uso individuais (ou familiares) constituem a base do pagamento pelos serviços ambientais neles contemplados, sendo definidos coletivamente pela comunidade que se co-responsabilizará pelo seu cumprimento 8 . Coloca-se, aqui, um desafio específico da territorialização num contexto agroextrativista caracterizado pela descontinuidade das áreas e dispersão das famílias.

Segundo o gestor, há resistências de vários Ministérios integrarem acordos de atuação conjunta em áreas ou territórios, com a consequiente geração de tensões. Entende que o Estado não foi feito para atuação territorial, predominando as políticas setoriais que são, elas mesmas, construtoras de espaços. Acrescente-se a resistência de governos estaduais (e mesmo municipais) às iniciativas "de cima para baixo" do Governo Federal, demandando diálogo permanente. Conflitos com o poder local podem dificultar, também, o recurso a organizações não-governamentais para a implementação de alguns programas. Apesar disso, relata exemplos de relações e parcerias "na ponta", como são a articulação de três programas de diferentes ministérios no Vale do Ribeira (SP) [Agenda 21, CONSAD e Território SDT], os pactos de concertação (como em Lages-SC)

8 Nota-se alguns pontos de contato entre esse instrumento e o Contrato Territorial de Estabelecimento (CTE) adotado na França e extinto em 2004, implementado na perspectiva de promover a multifuncionalidade da agricultura naquele país. 
construídos com apoio do Ministério do Planejamento, e na atuação junto ao Ministério de Integração Nacional no Rio S. Francisco, em projetos de micro-crédito e no direcionamento dos recursos para atividades sustentáveis.

Segurança alimentar e desenvolvimento territorial

A perspectiva de desenvolvimento territorial rural está presente, também, no âmbito do Programa Fome Zero lançado pelo governo Lula como estratégia de enfrentamento da fome e de promoção da segurança alimentar e nutricional. Isto se deu por meio do programa de instalação de Consórcios Intermunicipais de Segurança Alimentar e Desenvolvimento Local (CONSAD 's), com o propósito de fomentar iniciativas territoriais na forma de projetos de dinamização econômica que vinculassem a garantia de segurança alimentar com a promoção do desenvolvimento local. Oriundo do Programa Comunidade Ativa e dos Fóruns de Desenvolvimento Local Integrado e Sustentável (DLIS) promovidos pelo Governo FHC, os CONSAD 's ampliaram o foco para além das fronteiras municipais de modo a reunir grupos de municípios escolhidos por apresentarem baixos índices de desenvolvimento humano, pequena população e carências de infra-estrutura, entre outras.

Identificados os municípios e delimitadas as áreas de CONSAD's, basicamente, por meio de dados secundários (indicadores) compilados pelo IBAM, a implementação dos Consórcios envolveu a contratação de Entidades Implementadoras Regionais com a atribuição de apoiar a mobilização de atores locais e construir projetos supra-municipais pactuados entre organizações sociais e o poder público, aprovados nos fóruns dos CONSAD's respectivos. Chegoul-a à instalação de 40 CONSAD 's em diversas regiões do país (Ortega e Mendonça, 2007). Os critérios adotados levaram a que os CONSAD 's aglutinassem, sobretudo, pequenos e médios municípios com dinâmicas predominantemente rurais em áreas menos desfavorecidas do país. Da mesma forma, são agrícolas ou rurais os focos da maioria dos projetos apoiados pelo programa, revelando o viés para uma das dimensões da segurança alimentar. Ressalve-se, por fim, ter predominado nos critérios iniciais do programa um enfoque político-administrativo que tomou os municípios como referência para a delimitação espacial dos CONSAD ’s, referência esta que nem 
sempre contempla as dinâmicas sócio-econômicas presentes nas respectivas áreas e implica ajustes posteriores ou, quando estes não ocorrem, limitam a capacidade dos consórcios contemplarem tais dinâmicas. Em alguns dos estudos de caso da presente pesquisa, verifica-se a coexistência de "territórios" de CONSAD's e outros programas, com baixa ou inexistente articulação entre eles.

O Fome Zero envolve outro tipo de iniciativa com enfoque territorial relativa à construção de sistemas descentralizados de SAN, com ênfase em municípios de maior porte e regiões metropolitanas, com a perspectiva, segundo seu gestor, de dar territorialidade ao sistema alimentar. $\mathrm{O}$ foco principal dessa ação foge ao objeto da pesquisa, embora ela possa ter implicações para a questão agricultura familiar na medida em que envolva iniciativas de potencializar de relações de proximidade entre os equipamentos urbanos de alimentação e a produção agroalimentar local.

\subsection{Políticas de dinamização de atividades econômicas}

Arranjos produtivos locais

O Programa Arranjos Produtivos Locais foi estabelecido em 2004 para incrementar a capacidade competitiva das pequenas e medias empresas como resposta à abertura comercial implementada no inicio dos anos 1990. Avalia-se que este tipo de ação constitui condição necessária para que essas empresas possam atender tanto os mercados externos quanto os internos. Fundamenta-se na idéia que este tipo de empresas podem usufruir vantagens de uma localização favorável, e empreender um processo de desenvolvimento local com efeitos econômicos positivos para a coletividade (emprego e renda), sempre que elas se beneficiam de um apoio público dirigido à ampliação da competência dos recursos humanos por meio da aprendizagem e da inovação (GTP APL-MDIC, 2007).

A identificação e a seleção dos APL realizam-se mediante um processo pluri-institucional e participativo induzido por uma iniciativa proveniente do nível federal : o Grupo de Trabalho Permanente cuja secretaria técnica é lotada no MDIC. Em 2005, o programa 
identificou 957 arranjos produtivos trabalhados por 33 instituições governamentais e não-governamentais. Por se tratar de um Ministério sem capilaridade, a estratégia do programa baseia-se em núcleos estaduais de apoio constituídos pelos governos estaduais, integrantes do Sistema S e setor privado, bem como nos planos de desenvolvimento dos próprios APL's. A multiplicidade de setores e circunstâncias envolvidas pelo programa implica muitas parcerias na esfera federal, além daquelas no plano estadual.

Os "territórios", nesse caso, definem-se como conglomerados de municípios a partir de uma cidade-pólo, e são estabelecidos pelos Governos Estaduais ${ }^{9}$. Segundo o gestor do programa, a dimensão da governança é fundamental, pois os problemas principais referem-se à gestão e ao crédito. Assim, a escolha de 142 APL's prioritários adotou como critérios a existência de um setor organizado, um território, o número de indivíduos envolvidos e a estrutura de governança (sindicato, associação, etc.) e o foco em pequenas e médias empresas.

O estabelecimento de relações com a agricultura se faz na perspectiva da produção de matéria-prima. Assim, a cooperação com o MDA adota a ótica do agronegócio e da agroindústria, porém, com o enfoque em APL's, vale dizer, no plano local e em estratégias diferenciadas, em lugar do enfoque em cadeias produtivas que exige políticas para todos os elos das mesmas.

Desenvolvimento regional e ordenamento territorial

Em 2003, foi atribuída ao Ministério da Integração Nacional a competência, compartilhada com o Ministério da Defesa, das políticas de desenvolvimento regional e de ordenamento territorial do Brasil. Anteriormente, esta responsabilidade foi sucessivamente assumida pela Presidência da República de 1988 a $1999^{10}$ e pelo Ministério do Meio Ambiente de 1999 a 2003. Dentro do MIN, é a

9 Nota-se evidente semelhança com a concepção dos pólos de desenvolvimento lançada em 1957 por François Perroux, enfoque que influenciou inúmeras estratégias de desenvolvimento; no Brasil ela esteve presente, ao menos, desde as primeiras iniciativas da SUDENE.

10 Mais precisamente pela Secretaria de Assessoramento da Defesa Nacional subordinada ao Gabinete Militar de 1988 a 1990 e, posteriormente, pela Secretaria de Assuntos Estratégicos subordinada ao Departamento de Ordenação Territorial de 1990 a 1999. 
Secretaria do Desenvolvimento Regional (SDR) que está encarregada da formulação dessas políticas com a missão de contribuir para a redução das desigualdades regionais e promover a ativação dos potenciais do território em diferentes escalas: nacional, macrorregiões, mesorregiões, microrregiões e intra-urbano. Em 2003, a SDR decidiu concentrar seus esforços na implementação do Programa Nacional de Desenvolvimento Regional (PNDR) com prioridade para as zonas mais carentes, deixando para uma fase posterior a definição da Política Nacional de Ordenamento Territorial (PNOT). De fato, as políticas de desenvolvimento regional atravessaram um longo processo de redefinição. Depois dos Planos Nacionais de Desenvolvimento (PND) dos anos 1970, o planejamento nacional praticamente desapareceu durante os anos 1980 para ser re-introduzido no principio dos anos 1990. Mas, é só no final dos anos 1990, com a definição dos "eixos de desenvolvimento" no governo FHC, transformados depois em "eixos nacionais de integração e desenvolvimento", que o planejamento estratégico reafirmou-se e conseguiu definir linhas de ação compatíveis com a concepção do Estado como indutor de desenvolvimento.

As ações do PNDR no nível sub-regional foram definidas a partir de um mapeamento das desigualdades territoriais realizado pelo próprio programa. Um grande número de programas foi definido nas diversas escalas pertinentes e vieram a conformar o PPA 2004-2007. Foram construídos, por exemplo, (i) na escala macrorregional, os planos estratégicos de desenvolvimento sustentável das regiões Norte, Nordeste e Centro-oeste, (ii) na escala sub-regional, programas de desenvolvimento de áreas especiais, tais como a faixa de fronteira , do semi-árido, da BR 163 (Cuiabá - Santarém) etc. (iii) ainda na escala sub-regional, programas como o Promesco (Programas de Sustentabilidade de Espaços Subregionais), Promover (Programas de Promoção Econômica e Inserção Econômica de Sub-Regiões) e Produzir (Programa Organização Produtiva de Comunidades Pobres). O primeiro tipo de programa objetivava o desenvolvimento do potencial endógeno das mesorregiões diferenciadas, selecionando doze mesorregiões prioritárias em todo o país para serem atendidas no PPA 2004-2007. O segundo pretendia incentivar a emergência de arranjos produtivos locais e cadeias produtivas numa tentativa de compatibilizar competitividade e inclusão social. O terceiro era 
um programa conjunto com a FAO destinado a combater a situação de desemprego e subemprego em comunidades de baixa renda situadas nos territórios prioritários do PNDR.

Uma das maiores dificuldades enfrentadas pela Secretaria do Desenvolvimento Regional é a definição de ações de ordenamento territorial que sejam compatíveis com o novo referencial sobre o papel do Estado. Outra dificuldade, nos marcos do PNDR, é compatibilizar, simultaneamente, os objetivos de redução das desigualdades social e territorial e de dinamização econômica em territórios deprimidos. Um terceiro desafio tem a ver com o papel articulador da SDR com relação aos outros órgãos do Governo Federal para induzir dinâmicas de desenvolvimento territorial.

Observa-se que este programa está ainda em processo de definição e implementação tanto do ponto de vista conceitualmetodológico quanto operacional, numa tentativa de compatibilizar um instrumento clássico do estado desenvolvimentista com o novo referencial sobre o papel do Estado, conformando, de uma certa forma, um imenso laboratório de desenvolvimento territorial.

\section{Considerações finais}

Embora a pesquisa ainda não tenha sido concluída, faltando aprofundar a identificação e a discussão dos aspectos ligados à análise das comunidades e referenciais de políticas públicas, avançaremos algumas considerações com o propósito de explicitar as questões a serem ainda melhor trabalhadas e que orientarão a conclusão do estudo. Cabe lembrar que a pesquisa orienta-se por duas interrogações iniciais. A primeira volta-se para o processo de elaboração e organização das políticas territoriais rurais, enquanto que a segunda se refere ao papel das noções de MFA e de sustentabilidade nas políticas de desenvolvimento territorial.

Formação e organização das políticas públicas de desenvolvimento territorial

Não há dúvida que a elaboração da maior parte das políticas públicas territoriais mobilizou um grande número de técnicos e consultores ligados a atores institucionais fortemente implicados 
nos processos de desenvolvimento econômico, social e ambiental na área rural, notadamente, movimentos sociais, ong's, academia, administração pública e instituições financeiras. Isto é particularmente evidente no caso do PDTRS. Contudo, são necessárias investigações mais aprofundadas com vistas a saber se eles conformam uma rede ou uma comunidade de políticas públicas, e a conexão entre essas redes e comunidades. Para tanto, há que verificar a importância e estabilidade das relações entre esses técnicos e consultores, e as modalidades da sua interação com os gestores públicos.

Também não se questiona a existência de diferentes visões sobre o papel e a organização da agricultura familiar para a sociedade brasileira, assim como a tradução dessas visões em termos de políticas públicas. Pode-se até concordar que algumas dessas visões contribuíram na geração de normas coletivas que se cristalizaram em iniciativas locais ou regionais como, por exemplo, a agroecologia e sua utilização pelo programa de ação do pólo sindical da Borborema (PB) ou pela Articulação do Semi-Arido (ASA Nordeste). O que fica por analisar é como essas visões do mundo rural são utilizadas no processo de elaboração das políticas públicas e quais são os instrumentos de intervenção que foram criados a partir desses referenciais.

No que se refere ao dispositivo global das políticas públicas territoriais, observa-se a conformação de dois conjuntos articulados de políticas públicas. O primeiro conjunto é formado por diversas políticas especificas que priorizam uma entrada territorial para atingir de maneira mais eficiente um determinado público, portanto, tratam-se de políticas evidentemente segmentadas e diferenciadas. Esses são os casos dos programas APL (apoio à formação e ao funcionamento de conglomerados localizados de micro-empresas), PDTRS (conformação de territórios em beneficio do público preferencial do MDA: agricultores familiares, comunidades indígenas e remanescentes de quilombos, acampados e assentados), CONSAD 's (estimulo das produções alimentares oriundas da agricultura familiar com destino aos consumidores locais). Presume-se que boa parte dos programas do Ministério do Meio Ambiente podem ser classificados neste conjunto em razão de sua dupla preocupação, ambiental e social (Agenda 21, Proambiente). 
Um segundo conjunto seria composto pelo Programa Nacional de Desenvolvimento Regional da SDR/MIN, que se diferencia dos precedentes pela pretensão de ser um programa integrador dos demais programas. Os elementos desta integração são: (i) a idéia de reequilibragem social e territorial a partir da qual foram estruturadas as políticas específicas precedentes; (ii) a atribuição de uma missão oficial de coordenação nacional sobre o desenvolvimento territorial; (iii) a tentativa de construir um mapeamento geral da desigualdade em nível nacional o que permite posicionar, comparar, hierarquizar e selecionar as situações que necessitam um tratamento prioritário; (iv) a definição de escalas embutidas desde o nível nacional até o nível local que permite estabelecer uma coordenação vertical; (v) a disponibilidade de meios orçamentários de intervenção.

Concebido desta maneira, o dispositivo de políticas territoriais aparenta ter uma forte coerência. O ponto frágil é sua evidente sensibilidade com respeito ao mecanismo de coordenação, assim como repercutem sobre a eficiência da re-equilibragem a existência de "territórios específicos" e a coexistência de territórios dos programas num mesmo espaço geográfico. Relatos de gestores revelam que a iniciativa conduzida pela Câmara Interministerial de Política de Integração Nacional e Desenvolvimento Regional, localizada na Casa Civil da Presidência, com a intenção inicial de criar uma agenda compartilhada com enfoque ex ante de articulação de políticas, terminou se limitando ao tratamento ex post das ações já em curso, de modo que a intenção de uma política de desenvolvimento regional ficou restrita a iniciativas setoriais. Este dispositivo e, principalmente, as modalidades de seu funcionamento deverão ser precisadas na versão final desse relatório.

Relações entre enfoque territorial e multifuncionalidade

A junção do enfoque territorial com o olhar da MFA nos programas voltados para a agricultura familiar, o meio ambiente e o mundo rural, desdobra-se em três linhas para o aprofundamento das possibilidades desses programas e respectivos requisitos. A primeira linha se deve ao fato dessa junção propiciar dois focos possíveis e complementares para a integração ou articulação das ações e programas com vistas a um desenvolvimento territorial 
sustentável que promova os múltiplos papéis da agricultura familiar. De um lado, a integração com foco no território supõe compreender a unidade complexa constituída pelos espaços 'urbano' e 'rural' e pelos âmbitos municipal e supra-municipal. Ela também suscita ou favorece a emergência de temas relacionados com pobreza, desigualdade social, meio ambiente e outras questões que se imaginou ser possível tratar com uma ótica de desenvolvimento rural que o tornava quase sinônimo de desenvolvimento da produção agrícola. De outro lado, temos o foco na unidade familiar rural considerada como unidade complexa de produção - ou um 'sistema de atividades' agrícolas e não agrícolas ${ }^{11}$ - e gestora do território. Trata-se de uma perspectiva ainda muito incipiente nos programas agrícolas e rurais, porém, que já tem alguma importância nos programas ambientais que recorrem à noção de desenvolvimento sustentável, portanto, preocupados com a gestão dos recursos naturais envolvida nas atividades agrícolas das famílias rurais.

A segunda linha, decorrente da anterior, diz respeito à revisão do foco produtivo na "agricultura" familiar de modo a colocar as unidades familiares rurais como objeto de atenção dos programas, e não apenas os produtos que elas geram. Amplia-se, assim, o enfoque sobre os papéis desempenhados pelas famílias rurais nos respectivos territórios, "para além da produção". Caberia, nesse caso, explorar as possibilidades de redesenhar os instrumentos de apoio, por exemplo, com a introdução de um tipo de crédito "sistêmico" para a unidade familiar que não se limite ao convencional crédito baseado em produtos. $\mathrm{O}$ foco ainda insuficiente nas famílias rurais por parte dos programas agrícolas e de desenvolvimento rural contrasta com sua presença, obrigatória, nos programas 'não agrícolas', isto é, nas políticas sociais que abordam as famílias rurais no interior de programas de enfrentamento da pobreza e na promoção da seguridade social. A propósito, a interação entre ambos os tipos de programa - como a recente iniciativa de fazer o cruzamento dos cadastros do PRONAF e do Bolsa Família na região do Semi-Árido

11 A caracterização da unidade familiar rural como um sistema de atividades agrícolas e não agrícolas que provê bens privados e públicos foi desenvolvida no relatório correspondente ao Produto 3.4 (Parte I) da presente pesquisa. 
- têm produzido interessantes constatações sobre a dinâmica de reprodução das famílias rurais mais empobrecidas.

A introdução dos preceitos do enfoque da MFA nas políticas de desenvolvimento territorial contribuiria, ademais, para estimular dinâmicas de desenvolvimento que incluam categorias de agricultores familiares tradicionalmente deixadas à margem da modernização da agricultura e, talvez por esse próprio fato, não percebidas ("invisíveis") pelos programas públicos, mesmo pelas instâncias locais de concertação e implementação desses programas. Esse ponto tem relação com a questão da profissão de agricultor(a) que carece de avanços no estabelecimento de normas que a regulamentem, como também de instrumentos adequados para considerar os "fora da norma". Nesse aspecto, cabe verificar as iniciativas que visam tornar obrigatória a capacitação prévia para o recebimento de apoio público (crédito e outros), além daquelas dirigidas aos jovens agricultores.

A terceira linha de aprofundamento refere-se à institucionalidade dos programas e ações, começando pela questão da existência e eficácia dos espaços institucionais de interlocução intra-governo e com a sociedade, incluindo a dimensão da participação dos atores sociais em geral e das famílias rurais em particular. Esses espaços canalizam vários mecanismos de coordenação entre as modalidades de um mesmo programa, entre programas distintos e entre as esferas de governo ou planos de ação. Nesse ponto, ganha destaque a interação entre as diretrizes gerais (nacionais) dos programas, nas quais podem estar contemplados elementos dos enfoques da MFA e de desenvolvimento sustentável, e as perspectivas dos atores locais. Vale dizer, a interação inclui complementaridades e tensões bidirecionais entre as diretrizes ("de cima para baixo") e os interesses locais (“de baixo para cima”). A respeito desse último ponto, resta por ser verificada como se dá a incorporação do território nas estratégias e demandas de política dos atores não-governamentais.

A institucionalidade dos programas e ações engloba as relações que se estabelecem 'na ponta' entre os programas e os públicos por eles atendidos. A propósito, caberia explorar as possibilidades oferecidas por um tipo mais avançado de contratualização dessas relações. O estabelecimento de contratos públicos regendo as re- 
lações entre os organismos de Estado e as famílias atendidas pelos programas públicos, no caso, as famílias rurais, apresentaria duas vantagens, ambas importantes para a incorporação do enfoque da MFA. Os contratos são um instrumento para definir, implementar e monitorar compromissos recíprocos quanto a direitos e deveres entre o Estado e as famílias rurais/agricultores atendidos pelas políticas públicas. É possível conceber e implementar contratos de modo a contemplar a definição social (em espaços sociais) das prioridades de ação nos distintos territórios, a transparência na destinação de recursos públicos e incluir formas de participação e controle social.

Nesse sentido, a contratualização amplia as possibilidades de reunir diferentes formas de apoio às famílias rurais/agricultores em um único ou em poucos instrumentos (ou contratos), contribuindo para a desejada passagem do convencional enfoque setorial (agrícola) para um enfoque territorial. Pode-se, inclusive, vincular a eventual concessão de subsídios à provisão de bens públicos tais como a preservação do meio ambiente, da biodiversidade e das paisagens, o alívio da pressão antrópica nos centros urbanos ou a produção de alimentos de qualidade. Essa perspectiva coloca a questão dos processos que estabeleceriam as bases desse novo 'contrato social', isto é, as demandas atuais da sociedade brasileira em relação à agricultura e ao mundo rural, bem como as demandas dos próprios agricultores familiares. A título de ilustração, mencione-se as demandas sociais presentes nos debates contemporâneos sobre o papel das exportações, a oferta de alimentos de qualidade, a preservação do meio-ambiente e o recente tema da agroenergia, às quais se acrescentariam demandas específicas tais como mercados para os produtos da agricultura familiar e direitos sociais, entre outras.

Recebido em 5.3.2009

Aprovado em 10.4.2009

\section{Bibliografia}

BOUSSAGUET, L.; JACQOUT, S. \& RAVINET, P. Dictionnaire des politiques publiques. Paris, Les Presses de Sciences Po, 2004. 
FARIA, C.A.P.de. Idéias, Conhecimento e Políticas Públicas. Um inventário sucinto das principais vertentes analíticas recentes. Revista Brasileira de Ciências Sociais. Vol 18, n51. 2003.

GTP APL-MDIC. Oficina Regional de orientação à instalação de Núcleos Estaduais de Apoio a Arranjos Produtivos Locais. Documento de trabalho. 2007.

JOBERT, B. Représentations sociales controverses et débats dans la conduite des politiques publiques. Revue Française de Science Politique, numéro spécial "Les approches Cognitives des Politiques Publiques”, 50 (2) abril, 2000.

LE GALÉS, P. Régulation, Gouvernance et Territoires. In: COMMAILLE, J. \& JOBERT, B. (Dir.). Les Métamorphoses de la régulation politique. Paris: LGDJ, coll. Droit et Société, 1999.

MULLER, P. L'analyse cognitive des politiques publiques: vers une sociologie politique de l'action publique. Revue Française de Science Politique, numéro spécial "Les approches Cognitives des Politiques Publiques”, 50 (2) abril, 2000.

. Les politiques publiques. Paris: PUF, coll., 2006.

ORTEGA, A.C. \& MENDONÇA, N.C. Estratégias de desenvolvimento territorial rural no Brasil: continuidades e rupturas. In: ORTEGA, A.C. \& ALMEIDA FILHO, N. (Orgs.) Desenvolvimento territorial, segurança alimentar e economia solidária. Campinas: Alínea, 2007.

SCHNEIDER, S., CAZELLA, A. \& MATTEI, L. Histórico, caracterização e dinâmica recente do PRONAF. In: SCHNEIDER, S. et. al. (Orgs.). Políticas públicas e participação social no Brasil rural. P. Alegre: UFRGS, 2004.

SDT-MDA (a). Referências para uma Estratégia de Desenvolvimento Rural Sustentável no Brasil. Série Documentos SDT, n01. 2005.

\section{Abstract}

Policies of territorial development and the multi-functionality of family farming in Brazil.

Attempting to analyze the ways that public actions geared toward the rural enviroment have made reference to the notion of agricultural multifunctionality and the territorial perspective on development, in this article 
we analyze the variety of public policies that are part of the Multiple Year Plan 2004-2007. Within a context that is marked simultaneously by the globalization of the economy and strengthening of democratic processes, we give emphasis to public managers' concern for inducing a process of social and territorial re-balancing through the implantation of two different logics: sectoral policies that favor family farming and policies seeking to dynamize land-based economic activities. We note that these policies make implicit reference to the multi-functional character of family farming and explicit reference to the territorial perspective. In conclusion, we point to the essentially fragmented and differentiated nature of policies of rural development and the need to integrate them through clearer references to both notions.

Keywords: Sustainable territorial development, public policies, family farming, multiple year plans. 